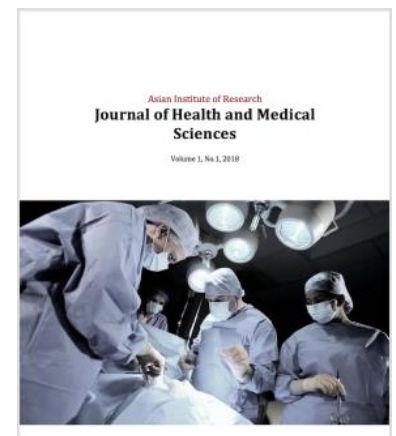

\title{
Journal of Health and Medical Sciences
}

\author{
Suhaila, Sulaiman, Basharudin, Mohamed, Hadi, Che Wail Abdul, Salleh, \\ Mohamed Shahadan, Nizan, Yusoff Khairul, and Yaziz, Mohd Isa Mohd. (2018), \\ Mental Health and Awareness of Child Abuse and Neglect (CAN); The Case \\ Among Parents in Malaysia. In: Journal of Health and Medical Sciences, Vol.1, \\ No.1, 14-20.
}

ISSN 2622-7258

DOI: 10.31014/aior.1994.01.01.3

The online version of this article can be found at: https://www.asianinstituteofresearch.org/

Published by:

The Asian Institute of Research

The Journal of Health and Medical Sciences is an Open Access publication. It may be read, copied and distributed free of charge according to the conditions of the Creative Commons Attribution 4.0 International license.

The Asian Institute of Research Journal of Health and Medical Sciences is a peer-reviewed International Journal. The journal covers scholarly articles in the fields of Medicine and Public Health, including medicine, surgery, ophthalmology, gynecology and obstetrics, psychiatry, anesthesia, pediatrics, orthopedics, microbiology, pathology and laboratory medicine, medical education, research methodology, forensic medicine, medical ethics, community medicine, public health, community health, behavioral health, health policy, health service, health education, health economics, medical ethics, health protection, environmental health, and equity in health. As the journal is Open Access, it ensures high visibility and the increase of citations for all research articles published. The Journal of Health and Medical Sciences aims to facilitate scholarly work on recent theoretical and practical aspects of Health and Medical Sciences. 


\title{
Mental Health Awareness of Child Abuse and Neglect (CAN); The Case Among Parents in Malaysia
}

\author{
Sulaiman Suhaila ${ }^{1}$, Mohamed Basharudin ${ }^{2}$, Che Wail Abdul Hadi ${ }^{3}$, Mohamed Shahadan Salleh ${ }^{4}$, Yusoff Khairul
} Nizan ${ }^{5}$, Mohd Isa Mohd Yaziz

\author{
1,2,3,4,5 Graduate School of Business, Universiti Tun Abdul Razak \\ ${ }^{6}$ Universiti Tun Abdul Razak
}

\begin{abstract}
This is a study on the state of awareness of Child Abuse \& Neglect (CAN) from 2012 to 2017 among parents in Malaysia. The study background is based on cases to the Department of Social Welfare according to the various types of CAN. The results show over the years an increasing number of reports. The study finds evidence that it is not an uncommon phenomenon in the country, in particular, physical maltreatment, neglect, and emotional maltreatment. It can be concluded that it is very crucial that CAN cases be monitored and managed properly and follow-up actions can be taken to educate parents about CAN.
\end{abstract}

Key Words: Child Abuse and Neglect (CAN), Reported Cases, States in Malaysia

\section{Introduction}

Child abuse or maltreatment as defined by the World Health Organization (WHO) is "all forms of physical and/or emotional ill-treatment, sexual abuse, neglect or negligent treatment or commercial or other exploitation" (WHO, 1999). Child abuse and neglect (CAN) have broad implications such as "actual or potential harm to the child's health, survival, development or dignity in the context of a relationship of responsibility and trust or power" (WHO, 1999). In addition, the CAN long-term impacts are not only limited to the victim but also on family and society psychosocial consequences, juvenile misbehaviour, substance abuse and crime (Fry D, McCoy A, Swales D, 2012). CAN also have some potential to affect the state's economics. The economic impact of CAN is also considered substantial. WHO estimated that economic value of Disability Adjusted Life Year (DALY) lost increasing from $1.24 \%$ to $3.46 \%$ of Gross Domestic Product (GDP) across sub-regions in the Asia and Pacific region. If we update it to the year 2018 dollars, the estimated economic burden will be totalled up to US194 billion dollars. CAN implications to the victim, family, society and country as mentioned above, indicates the importance of preventing and responding to CAN at every level (Fang X, Fry DA, Brown DS, Mercy JA, Dunne MP, Butchart AR, 2015).

Malaysia had ratified the United Nation (UN) Convention of the Rights of the Child (CRC) since the year 1995. With this rectification, Malaysia recognises the universally accepted right of the child as contained within this convention. This mean, Malaysia also recognised the UN Convention on the Elimination of All Forms of Discrimination against Women (Department of Women's Affairs Malaysia, 1999). The Ministry of Women, 
Family and Community Development have been tasked by the government of Malaysia to lead and coordinate any issues regarding women, family and children there on.

In the past, the public, often perceived cases of CAN as an isolated case rather than part of a widespread phenomenon. As a result, CAN do not receive universal attention until the late 1980s when a few high-profile CANs were highlighted and emphasised in the media (Mohd Yusoff, JZ, 2001). These appeared as the catalyst to motivate the Malaysian Government to introduce the Child Protection Act in the year 1991. Subsequently, the one-stop crisis centres were also set up in Government hospitals around Malaysia beginning the middle of the year 1998. These centres are functioned to provide services for victims of domestic violence, sexual assault and child abuse (Department of Women's Affairs Malaysia, 1999). In order to strengthen actions in cooping this phenomenon, in April 1998, the Government initiated a hotline (Mohd Yusoff, JZ, 2001). Later, in an attempt to deal more effectively with issues relating to children, the Government introduced the Child Act 2001 to supersede the Child Protection Act 1991.

The Child Act 2001 defined child abuse as "when the child has been or is at substantial risk of being physically or emotionally injured or sexually abused or neglected in terms of adequate care, food, shelter, clothing, medical attention, supervision and safety, or abandonment or others such as being on the street or used for begging by the parents or persons in charge of the child at any one time (Laws of Malaysia, Child Act 2001). Under the Child Act 2001 also, it is mandatory for doctors, family members and the public members to report all cases of suspected CAN to the relevant authorities. Data on reported CANs are compiled annually mainly by the Department of Social Welfare, the Royal Malaysian police, and various hospitals.

\section{Literature Review}

There are relatively limited studies on child abuse occurrence in Malaysia. The earliest child sexual abuse incidence study was published in 1996. Singh and Colleagues (1996) conducted a self-administered survey among 616 student nurses and trainees of Medical Assistants. Their survey indicated that about $6.8 \%$ of the respondents reported being sexually abused during the childhood of which $8.3 \%$ females and $2.1 \%$ were males. Less than $1 \%$ reported having experienced sexual penetration. Sexual abuse was reported to have begun under 10 years of age in $38.1 \%$ of the cases. About two-thirds of them were reported repeatedly abused, and one-third of them experienced abuse from more than one abuser. About $71.4 \%$ of the abusers were persons known to the respondents. A marked difference in incidence between ethnic groups was found where more Chinese reported being sexual abuse victims than Malay and Indian. However, it cannot be determined if this was a result of under-representation from Chinese respondents or under-reporting of other ethnic groups due to local sociocultural limitations in disclosing abuse. Kamaruddin (2000) had cited several barriers to reporting of sexual abuse including societal discrimination against people who have been sexually abused, cultural taboos in relation to 'losing face' and lack of specialised 'one-stop' centres at the time for the sexually abused (Kamaruddin, 2000). Though the target sample of Singh et al. study may not be entirely reflective of the population due to the underrepresentation of Chinese and non-random sampling limiting the generalisability of the results, this study marked the beginning of systematic examination on the degree of the CAN at the population level in Malaysia.

Subsequent community-based studies had measured CAN among school students (Choo WY, Dunne MP, Marret MJ, Fleming M, Wong YL, 2011) (Ahmed A, Wan-Yuen C, Marret MJ, Guat-Sim C, Othman S, Chinna K., 2015), trainees in national service camps (Chan LF, Maniam T, Saini SM, Shah SA, Loh SF, Sinniah A, et al, 2013) and incarcerated youths (Ahmad A, Mazlan NH, 2014). Choo and colleagues (2011) conducted a crosssectional survey among 1,870 students aged 16 years attending 20 randomly selected urban and rural secondary schools in the year 2005 in Selangor (Choo WY, Dunne MP, Marret MJ, Fleming M, Wong YL, 2011). In this survey, emotional and physical abuse were the most common forms of child abuse reported.

More recently, a separate cross-sectional study involving 3509 respondents of 10 to 12 years old children selected using a random sampling of public primary schools in Selangor estimated the incidence of parental physical and emotional maltreatment, parental neglect and teacher-inflicted physical maltreatment (Ahmed A, Wan-Yuen C, Marret MJ, Guat-Sim C, Othman S, Chinna K., 2015). Three-quarters of 10 to 12 years old 
children reported at least one form of maltreatment, with parental physical maltreatment being most common. The prevalence of parental physical maltreatment (53\%), approaches the upper end of the range of physical abuse recorded in surveys from other countries reported in East Asia and the Pacific region - from as low as $0.4 \%$ for very severe abuse to as high as $66.3 \%$ for moderate physical abuse (UNICEF EAPRO, 2012). Teacherinflicted physical maltreatment was reported by $29 \%$ whilst approximately 1 in 5 children reported being emotionally maltreated. Males had higher odds of all types of maltreatment except for emotional maltreatment Ahmed A, Wan-Yuen C, Marret MJ, Guat-Sim C, Othman S, Chinna K., 2015).

\section{Analysis}

Table I below shows the annual data of reported CAN cases to the Department of Social Welfare according to the various types of CAN, showing increasing numbers of reports.

Table I: Total Cases of CAN Reported to Department of Social Welfare, Malaysia from 2004-2017 According to Type of Abuse

\begin{tabular}{|l|c|c|c|c|c|c|}
\hline Year & 2012 & 2013 & 2014 & 2015 & 2016 & 2017 \\
\hline Abandoned & 121 & 98 & 26 & 68 & 53 & 63 \\
\hline Neglect & 357 & 389 & 563 & 601 & 682 & 761 \\
\hline Physical & 354 & 410 & 445 & 431 & 495 & 586 \\
\hline Sexual $*$ & 324 & 430 & 529 & 566 & 679 & 754 \\
\hline Incest & NA & NA & 30 & 57 & 49 & 21 \\
\hline Emotional & 32 & 32 & 63 & 77 & 50 & 45 \\
\hline Others & 54 & 31 & 0 & 0 & 0 & 49 \\
\hline Total & 1242 & 1390 & 1656 & 1800 & 1999 & 2279 \\
\hline
\end{tabular}

Source: Department of Social Welfare, 2018

Note: *Excludes incest if figures for incest available NA - Not Available

Next, in Chart, I below shows the trajectory of a number of reported CAN cases in Malaysia from the year 2012 to the year 2017 according to the various types of CAN, showing increasing numbers of reports.

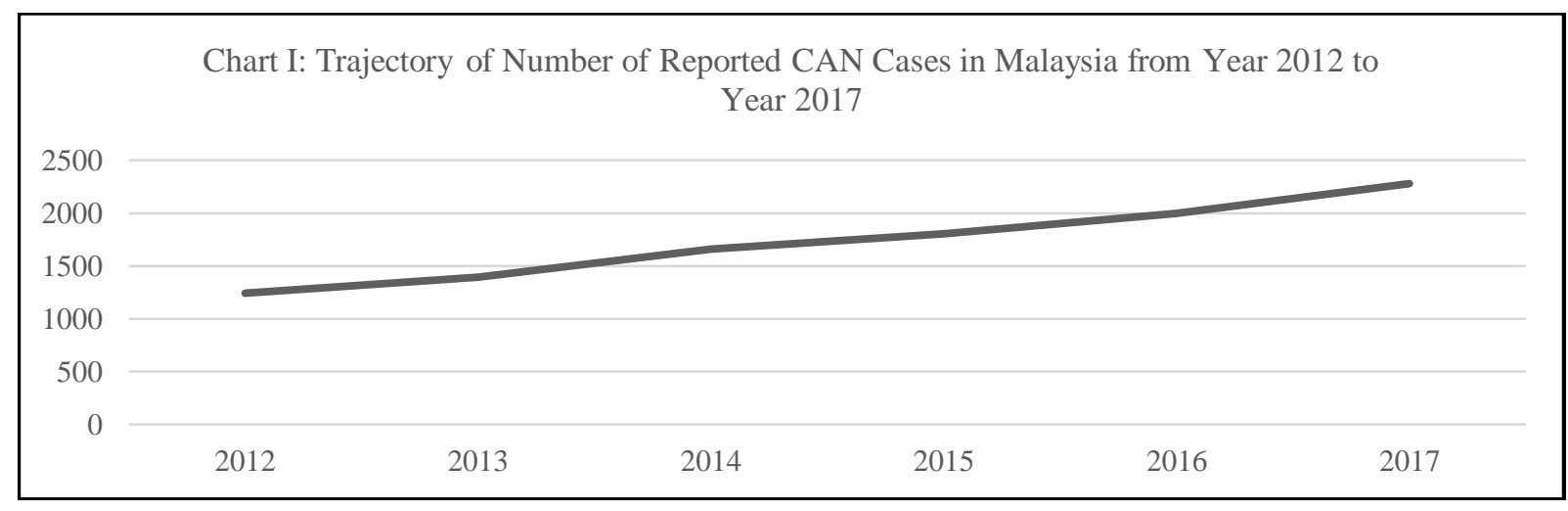

The number of reported CAN cases in Malaysia as shown in Chart I above increased for almost double from 1242 cases in the year 2012 to 2279 cases in the year 2017. 


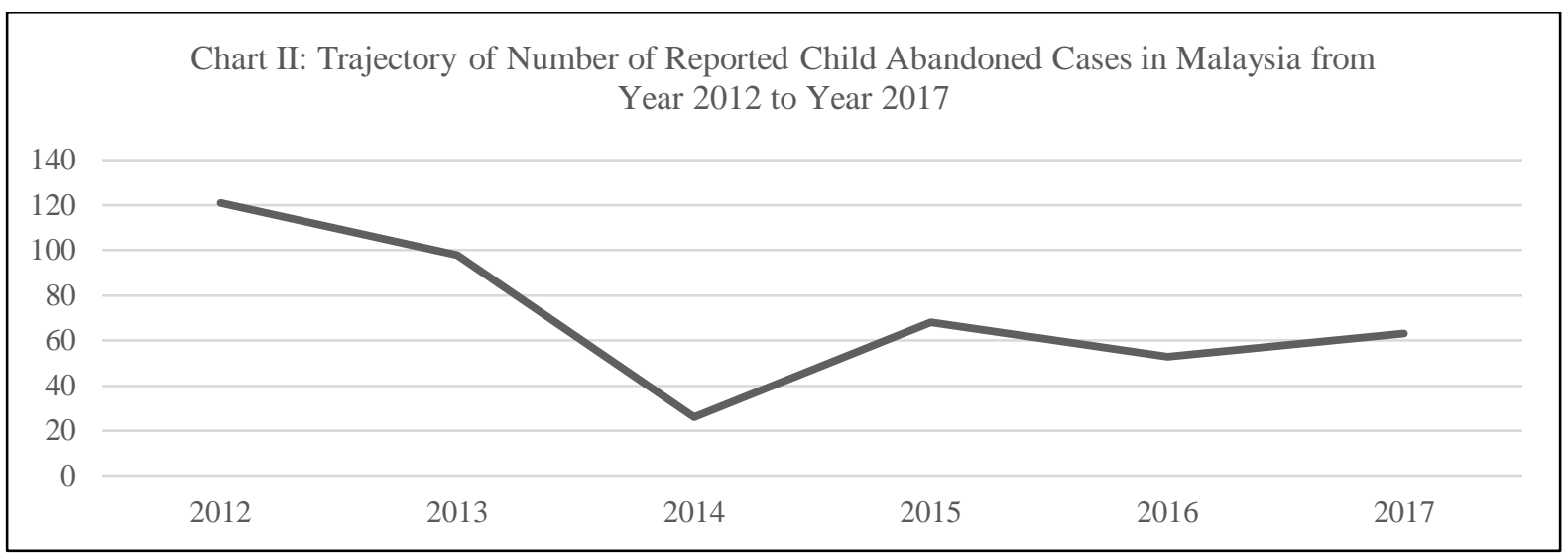

Chart II at the top shows the trajectory of a number of reported Child Abandoned cases in Malaysia from the year 2012 to the year 2017. The number of reported Children Abandoned cases decreased from 121 cases in the year 2012 to 98 cases in the year 2013 and further decreased to 26 cases in the year 2014. However, it increased to 68 cases in the year 2015 and to 63 cases in the year 2017.

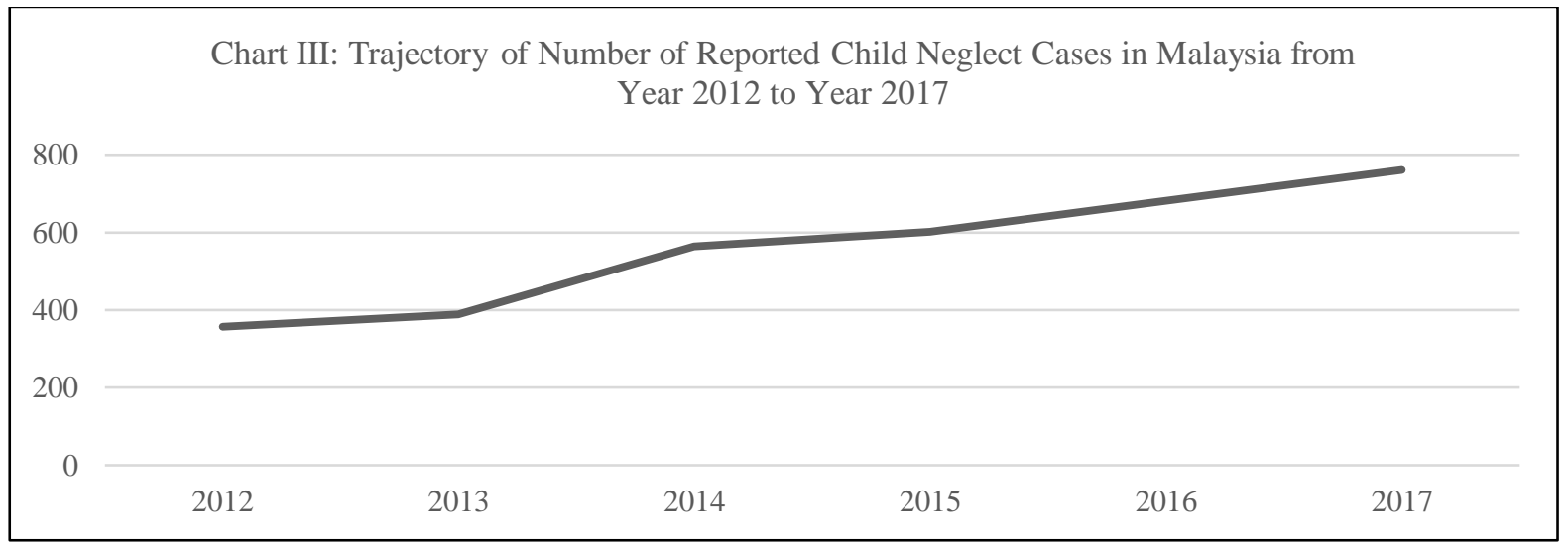

Chart III above shows the trajectory of a number of reported Child Neglect cases in Malaysia from the year 2012 to the year 2017. The number of reported Child Neglect cases increased from 354 cases in the year 2012 to 563 cases in the year 2014 and further increased to 761 cases in the year 2017.

In addition, Chart IV at the bottom below shows the trajectory of a number of reported Child Physical Abuse cases in Malaysia from the year 2012 to the year 2017. The number of reported Child Physical Abuse cases increased from 357 cases in the year 2012 to 431 cases in the year 2015 and further increased to 586 cases in the year 2017.

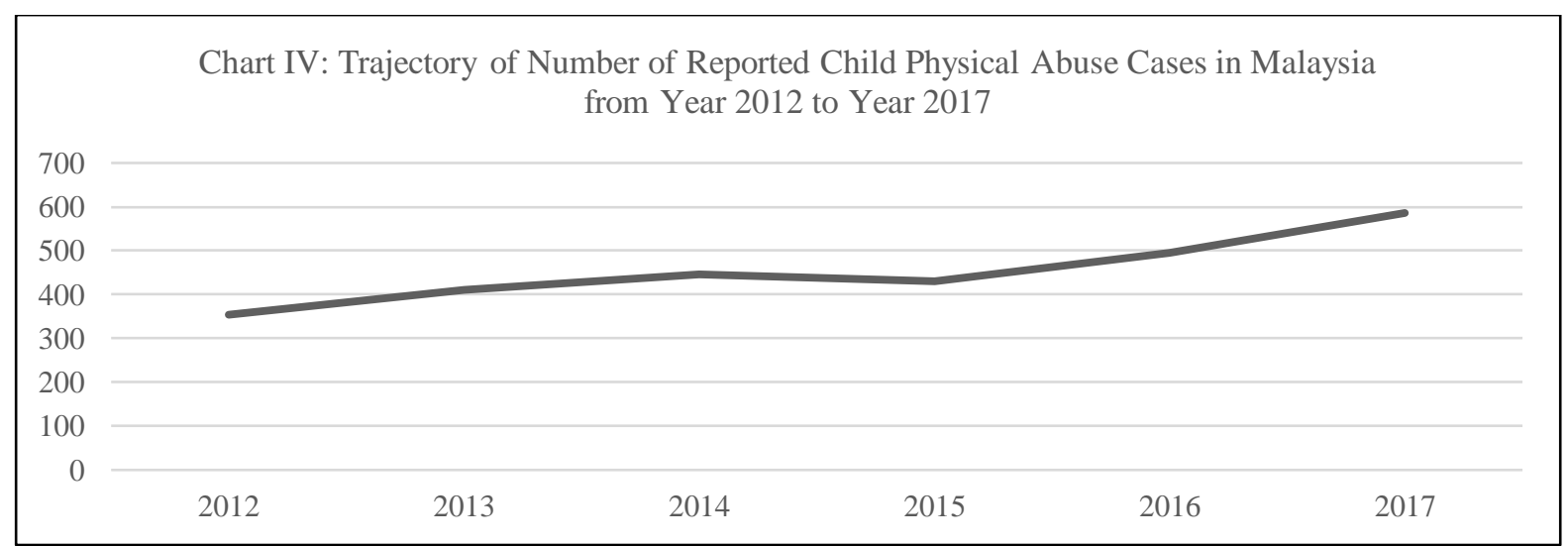

Next, Chart V shows the trajectory of a number of reported Child Sexual Abuse cases in Malaysia from the year 2012 to the year 2017. The number of reported Child Sexual Abuse cases increased from 324 cases in the year 2012 to 566 cases in the year 2015 and further increased to 754 cases in the year 2017. 


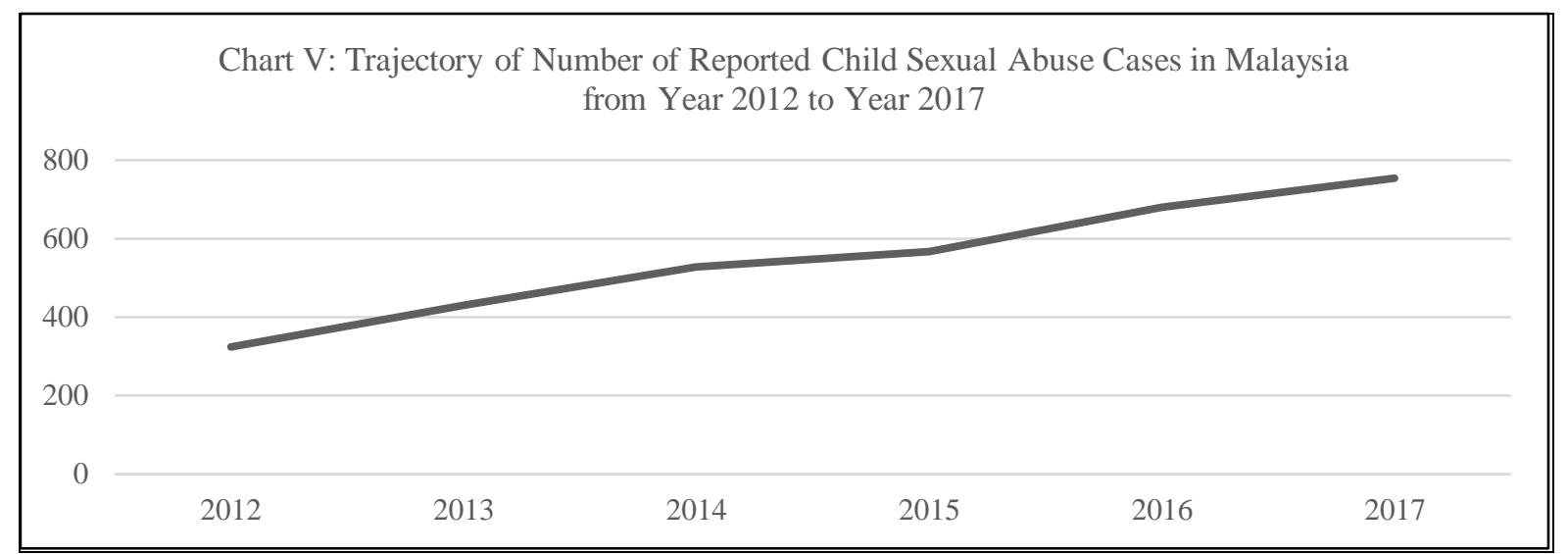

Chart VI shows the trajectory of the number of reported Child Incest Abuse cases in Malaysia from the year 2012 to the year 2017. The number of reported Child Incest Abuse cases were increased from no cases in the year 2012 to 30 cases in the year 2014 and further increased to 57 cases in the year 2017. However, the cases decreased to 49 cases in the year 2016 and further decreased to 21 cases in the year 2017.

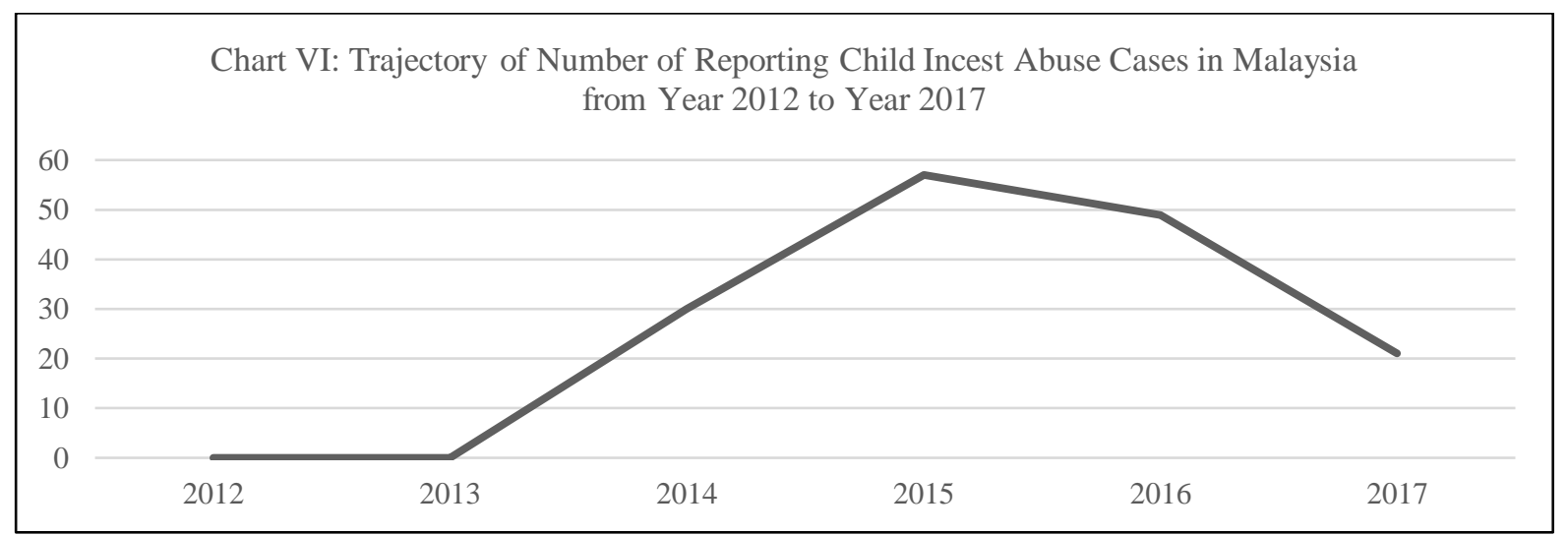

Chart VII show the trajectory of the number of reported Child Emotional Abuse cases in Malaysia from the year 2012 to the year 2017. The number of reported Child Emotional Abuse cases were increased from 32 cases in the year 2012 to 77 cases in the year 2015. However, the cases decreased to 50 cases in the year 2016 and further decreased to 45 cases in the year 2017.

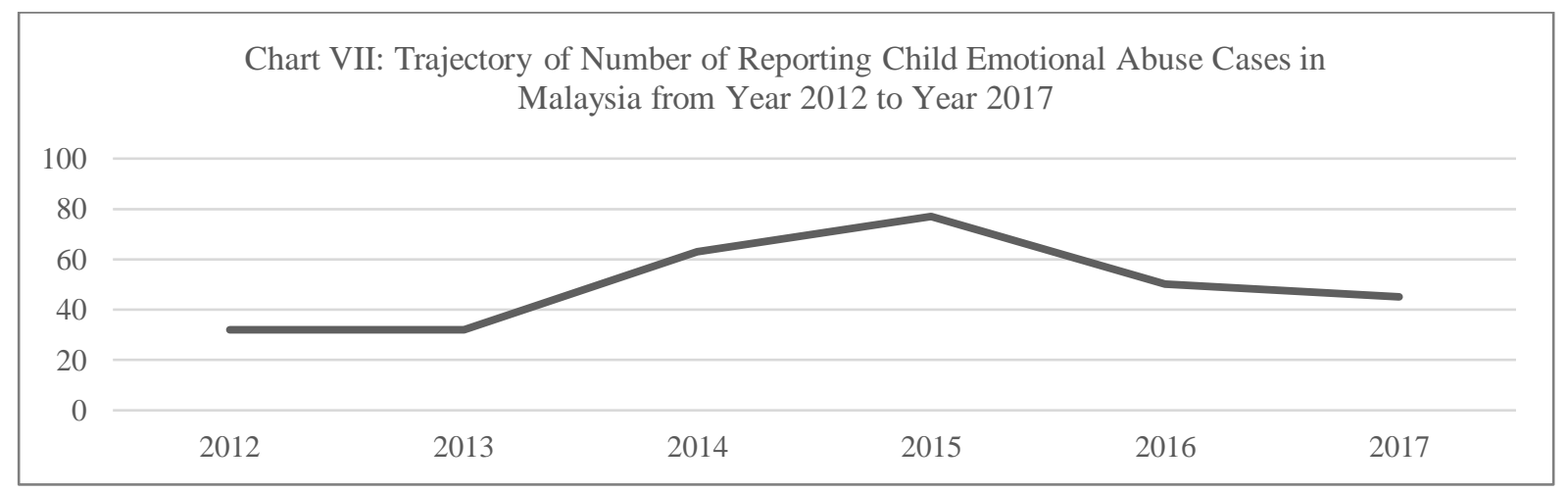

Table II: Total Cases of CAN Reported to Department of Social Welfare, Malaysia from the Year 2012 to the Year 2017 According to the States

\begin{tabular}{|l|c|c|c|c|c|c|c|}
\hline Year & 2012 & 2013 & 2014 & 2015 & 2016 & 2017 & Total \\
\hline Perlis & 21 & 16 & 26 & 30 & 44 & 27 & 164 \\
\hline Kedah & 39 & 63 & 26 & 66 & 102 & 54 & 350 \\
\hline Pulau Pinang & 130 & 131 & 154 & 131 & 184 & 216 & 946 \\
\hline Perak & 80 & 131 & 145 & 172 & 147 & 185 & 860 \\
\hline Selangor & 412 & 368 & 474 & 446 & 498 & 816 & 3014 \\
\hline Kuala Lumpur & 269 & 153 & 287 & 415 & 435 & 444 & 2003 \\
\hline
\end{tabular}




\begin{tabular}{|l|c|c|c|c|c|c|c|}
\hline Negeri Sembilan & 40 & 55 & 67 & 124 & 147 & 171 & 604 \\
\hline Melaka & 24 & 65 & 64 & 26 & 31 & 55 & 265 \\
\hline Johor & 115 & 156 & 126 & 115 & 91 & 163 & 766 \\
\hline Pahang & 27 & 8 & 38 & 56 & 91 & 46 & 266 \\
\hline Terengganu & 20 & 17 & 33 & 16 & 41 & 23 & 150 \\
\hline Kelantan & 11 & 31 & 51 & 14 & 8 & 19 & 134 \\
\hline Sabah & 17 & 19 & 21 & 0 & 0 & 19 & 76 \\
\hline Sarawak & 36 & 176 & 144 & 189 & 180 & 41 & 766 \\
\hline Labuan & 1 & 1 & 0 & 0 & 0 & 0 & 2 \\
\hline Total & 1242 & 1390 & 1656 & 1800 & 1999 & 2279 & 10366 \\
\hline
\end{tabular}

Source: Department of Social Welfare, 2018

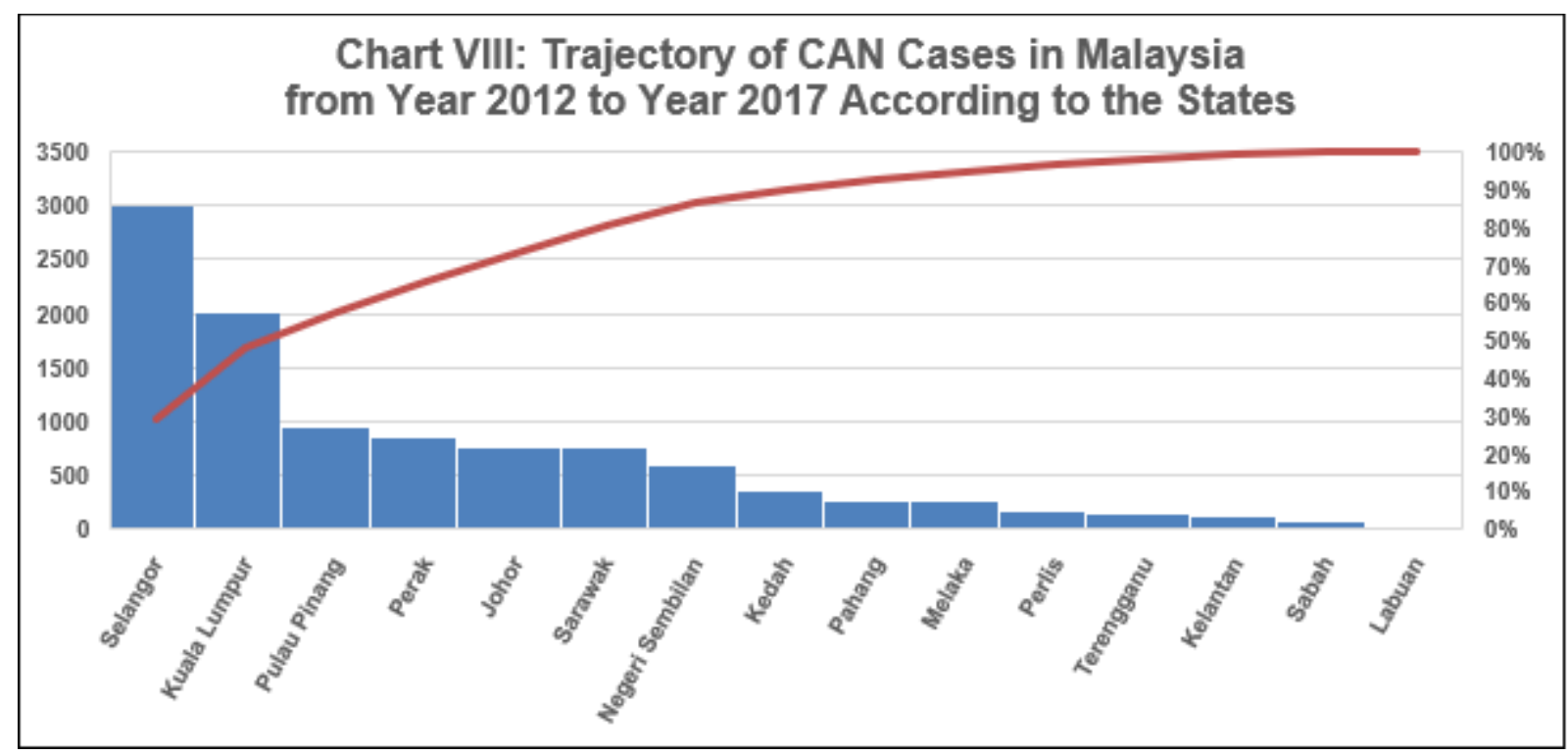

As shown in Table II and Chart VII, for the year 2012 to year 2017, the State of Selangor recorded the highest CAN cases (3014 cases), followed by Kuala Lumpur (2003 cases) and Pulau Pinang (946 cases) and the lowest was Labuan (2 cases), Sabah (76 cases) and Kelantan (134 cases).

\section{Conclusion}

The prevalence figures reported in these studies support the observation that CAN is not an uncommon phenomenon in Malaysia, in particular, physical maltreatment, neglect, and emotional maltreatment. More importantly, child sexual abuse ("the involvement of a child in sexual activity that he or she does not fully comprehend, is unable to give informed consent to or for which the child is not developmentally prepared and cannot give consent") (WHO, 1999) is far more prevalent than actually reported to the authorities.

Due to this serious phenomenon, it is very crucial that CAN cases be monitored and managed properly. So much so, the study of the Awareness of CAN Among Parents in Malaysia will definitely determine the current awareness status of the parents, and consequently, follow-up actions can be taken to educate parents about CAN with a view of reducing the CAN case in Malaysia.

\section{References}

Anda RF, Butchart A, Felitti VJ, Brown DW. Building a Framework for Global Surveillance of the Public Health Implications of Adverse Childhood Experiences. Am J Prev Med 2010; 39(1): 93-8.

Fry D, McCoy A, Swales D. The consequences of maltreatment on children's lives: a systematic review of data from the East Asia and Pacific Region. Trauma, Violence \& Abuse 2012; 13(4): 209-33.

Fang X, Fry DA, Brown DS, Mercy JA, Dunne MP, Butchart AR, et al. The burden of child maltreatment in the East Asia and Pacific region. Child abuse \& neglect 2015; 42: 146-62.

Department of Women's Affairs Malaysia. Report of convention on the elimination of all forms of discrimination against women (CEDAW). Kuala Lumpur, Malaysia: Ministry of National Unity and Social Development (draft), 1999. 
Mohd Yusoff, JZ. Protective Measures and Remedies for The Weaker Partner in a Family and Child Abuse Cases: The Malaysian Perspective. LAWASIA Conference 2001, New Zealand.

Report of the consultation on child abuse prevention, 29-31st March 1999 World Health Organisation 1999(document WHO/HSC/PVI/99.1).

Singh HS, Yiing WW, Nurani HN. Prevalence of childhood sexual abuse among Malaysian paramedical students. Child abuse \& neglect 1996; 20(6): 487-92.

Kamaruddin Z. A Malaysian perspective. In: Freeman M, editor. Overcoming child abuse: A window on a world problem. Child abuse and neglect. Dartmouth: Ashgate; 2000. p. 257-80.

Choo WY, Dunne MP, Marret MJ, Fleming M, Wong YL. Victimization experiences of adolescents in Malaysia. Journal of adolescent health 2011; 49(6): 627-34.

Ahmed A, Wan-Yuen C, Marret MJ, Guat-Sim C, Othman S, Chinna K. Child maltreatment experience among primary school children: a large-scale survey in Selangor state, Malaysia. PloS one. 2015; 10(3): e0119449.

Chan LF, Maniam T, Saini SM, Shah SA, Loh SF, Sinniah A, et al. Sexual abuse and substance abuse increase risk of suicidal behavior in Malaysian youth. Asia-Pacific psychiatry. 2013; 5 Suppl 1: 123-6.

Ahmad A, Mazlan NH. Substance Abuse and Childhood Trauma Experiences: Comparison between Incarcerated and Non-incarcerate Youth. Procedia - Social and Behavioral Sciences. 2014; 113(0): 161-70.

Finkelhor D, Shattuck A, Tyrner H, Hamby S. The lifetime prevalence of child sexual abuse and sexual assault assessed in late adolescence. J Adolescent Health. 2014; 55(3): 329-33.

Nguyen HT, Dunne MP, Le AV. Multiple types of child maltreatment and adolescent mental health in Viet Nam. Bulletin of the World Health Organization. 2010; 88(1): 22-30.

Tran QA, Dunne MP, Vo TV, Luu NH. Adverse Childhood Experiences and the Health of University Students in Eight Provinces of Vietnam. AsiaPacific journal of public health. 2015; 27(8 Suppl): 26s-32s.

Lin D, Li X, Fan X, Fang X. Child sexual abuse and its relationship with health risk behaviours among rural children and adolescents in Hunan, China. Child abuse \& neglect. 2011; 35(9): 680-7.

UNICEF. Measuring and Monitoring Child Protection Systems: Proposed Core Indicators for the East Asia and Pacific Region. Bangkok: UNICEF EAPRO, 2012.

Kasim MS, Shafie HM, Cheah I. Social factors in relation to physical abuse in Kuala Lumpur, Malaysia. Child abuse \& neglect. 1994; 18(5): 401-7. 